\title{
Desarrollo y cooperación
}

LACALLE, M. C. (Coord.) (2010), Glosario básico sobre microfinanzas, Madrid, Ed. Foro Nantik Lum de Microfinanzas, 146 pp.

El texto que se ha publicado recientemente y que reseñamos de forma breve es el cuaderno monográfico número 12 del Foro Nantik Lum de Microfinanzas, en el que se reflexiona acerca de los conceptos básicos de las microfinanzas, ampliando y actualizando el contenido del cuaderno número 5 editado hace cuatro años. El objetivo que se persigue es el mismo que entonces: aportar luces a la discusión sobre el significado de los principales términos y conceptos utilizados en el sector microfinanciero y a su práctica².

Como cualquier otro colectivo, el sector de las microfinanzas es un grupo vivo en el que los agentes, las instituciones y las prácticas van cambiando para adaptarse a las circunstancias que se van modificando y que van dando lugar a una realidad distinta: todos estos aspectos justifican la necesidad de reflexionar periódicamente sobre los principales conceptos que se manejan en este sector no sólo para facilitar el entendimiento entre los agentes implicados o que pertenecen a este mundo, sino también para acercarse a las principales líneas de debate que se abren en la actualidad sobre ellos. Para ello, a diferencia de otros cuadernos monográficos, se han agrupado los conceptos en distintos grupos que son analizados por especialistas en cada una de las materias, lo que ha dado lugar a una obra de carácter colectivo. Así, en cada apartado, cada autor o autores analiza en primer lugar el significado del concepto o conceptos a los que se refiere y, a continuación, repasa las principales líneas de debate y reflexiones que existen en torno a dichos conceptos.

Los once apartados en los que se ha dividido esta obra, así como los conceptos analizados en cada uno, son los siguientes:

1. Del microcrédito a las microfinanzas, que se ocupa, además, de la definición y tipología de las instituciones microfinancieras.

2. Pobreza, exclusión social y exclusión financiera.

3. Tipo de interés, autosuficiencia operativa y autosuficiencia financiera, alcance y escala.

4. Desempeño financiero, desempeño social y acceso a la financiación por parte de las instituciones microfinancieras.

5. Aval, garantía, morosidad, fallido y carencia.

6. Metodologías.

7. Otros productos y servicios microfinancieros.

8. Regulación y supervisión del sector microfinanciero.

9. Medio ambiente y microcréditos: llegan las microfinanzas verdes.

${ }^{2}$ M. C. Lacalle, p. 16 
10. Una mirada comparativa de las microfinanzas en seis regiones del mundo

\section{Empresa social.}

Como se observa en la relación anterior, los temas analizados abarcan la práctica totalidad de las cuestiones claves relacionadas con el mundo de las microfinanzas, al tiempo que proporcionan una visión actualizada de los aspectos más relevantes del sector. Resulta de especial interés conocer los datos aportados en el apartado relativo a la situación de las microfinanzas en seis regiones del mundo, pues aporta información cualitativa y cuantitativa acerca de la situación del sector en las siguientes zonas: África Subsahariana, Asia del sur, Asia oriental y Pacífico, Europa oriental y Asia central, Latinoamérica y Caribe y Medio oriente y África del norte. Con todo ello, se obtienen datos que permiten extraer algunas reflexiones sobre el grado de desarrollo de las microfinanzas en cada una de ellas y sobre los modelos aplicados en cada caso. Así, las dos zonas que tienen más "tradición" en este campo y que, en principio, podríamos considerar más importantes: Asia y Latinoamérica, presentan características muy distintas. Así, mientras en Asia las microfinanzas están orientadas a alcanzar a los más pobres de entre los pobres (lo que da lugar a que concentre la mayor proporción de instituciones y clientes, pero sólo un reducido porcentaje de la cartera total de créditos), en Latinoamérica, aunque se atiende a clientes de bajos ingresos, no se alcanza a los más pobres y las entidades están abocadas fuertemente al desarrollo del sector microempresarial de los países (lo que explica que en esta zona se concentre la mayor parte de la cartera de microcréditos, aunque el porcentaje de entidades y clientes sea bastante inferior).

A pesar del interés de estos detalles, se plantea el problema de que se refieren al año 2007, con lo que los efectos de la actual crisis financiera aún no se manifiestan y se desconoce, por tanto, en qué medida ésta habrá afectado al sector. En relación con este tema, recordemos, además, que precisamente los problemas derivados de la crisis han provocado que se modifiquen las normas de solvencia que deben cumplir las entidades financieras, llevando al denominado sistema de Basilea III. Cómo las entidades de microfinanzas pueden verse afectadas por este nuevo sistema y por el actual (Basilea II) es una cuestión que tampoco se aborda en este texto.

No obstante los inconvenientes mencionados (la falta de las referencias más recientes y la posible influencia de las nuevas normas de solvencia), el texto que reseñamos aporta información abundante y actualizada en la medida de lo posible, lo cual es importante, pues con ello contribuye a aportar transparencia a este sector en ocasiones escasamente conocido, especialmente en los países menos desarrollados y emergentes. En este sentido, debemos tener en cuenta que la información contenida en esta obra puede completarse con el contenido de otro de los cuadernos editados por el Foro Nantik Lum, de J. BAYO y otros, cuyo título es Microcréditos en la Unión Europea. [ $\mathrm{M}^{\mathrm{a}}$ del Carmen López Martín] 